\title{
RANCANG BANGUN E-COMMERCE SEBAGAI SARANA PENINGKATAN PEREKONOMIAN BAGI INDUSTRI KECIL DAN MENENGAH DI KABUPATEN BREBES
}

\author{
Rais ${ }^{1}$, Eko Budihartono ${ }^{2}$ \\ Email : ${ }^{1}$ rais.hojawa@gmail.com, ${ }^{2}$ tara.niscita@gmail.com \\ Prodi DIII Teknik Komputer, Politeknik Harapan Bersama \\ Jl. Mataram No. 9 Pesurungan Lor Tegal
}

\begin{abstract}
Abstrak
Kabupaten Brebes terkenal dengan produk unggulanya seperti telur asin, batik tulis dan bawang merah namun pemasaranya masih konvensional melalui transaksi klasik. Kesulitan melakukan promosi dan pemasaran secara online menjadikan kendala utama bagi para pelaku IKM karena masih banyaknya pelaku IKM yang belum dapat pemanfaatan teknologi informasi dan komunikasi. Permasalahan ini dapat diatasi dengan dibangunya $e$-commerce sebagai sarana pemasaran. E-commerce dibuat dengan tujuan menyatukan para Pelaku IKM di Kabupaten Brebes serta menjebatani para pelaku IKM dengan konsumen di luar Kabupaten untuk dapat bertransaksi secara online. Pada penelitian ini e-commerce dibangun dengan metode SDLC (System Development Life Cycle) agar mudah dalam perencanaanya serta menggunakan metode pengujian black box untuk mengetahui fungsional dari website $e$ commerce tersebut. Hasil penelitian ini dapat meningkatkan perekonomian di Kabupaten Brebes serta meningaktnya pendapatan para pelaku industri kecil dan menengah.
\end{abstract}

Kata Kunci - IKM Kabupaten Brebes, E-commerce, Black Box

\section{Pendahuluan}

Indonesia merupakan pasar terbesar ecommerce di Asia Tenggara, menurut data Euromonitor (2014), penjualan online di Indosesia mencapai U\$\$ 1,1 miliar lebih tinggi dari Thailand dan Singapura. Pertumbuhan ekonomi di Indonesia dipengaruhi banyak faktor, salah satunya adalah Industri Kecil dan Menengah (IKM). Pemerintah mendukung IKM dengan membentuk Kementrian Koperasi dan Usaha Kecil menengah pada tahun 2014. Kebijakan Presiden mengenai Koperasi dan Usaha Kecil Menengah berperan penting dalam mengatasi permasalahan IKM yang ada di Indonesia [1]. Demikian halnya yang disampaikan Bupati Brebes. Hj. Ida Priyanti, SE dalam acara pembinaan UKM/IKM Kabupaten Brebes yang diselenggarakan oleh Dinas Perindustrian dan Perdagangan (Disperindag) pada kamis, 22 Mei 2014. Secara khusus Bupati juga menyampaikan kebanggaanya atas dunia usaha kita yang terus berkembang. Jumlah industri dan usaha kecil dikabupaten brebes misalnya, selalu mengalami kenaikan baik dari sisi jumlah pengusaha, unit usaha, permodalan maupun tenaga kerja yang diserap.

Kabupaten Brebes terkenal dengan produk unggulan seperti telur asin, batik tulis, keramik, rebana dan bawang merah yang selalu menjadi favorit bagi para wisatawan local maupun para pemudik yang singgah setelah perjalanan jauh, namun ternyata Kabupaten Brebes tercatat sebagai kabupaten dengan Indeks Pembangunan Manusia (IPM) yang terendah di Provinsi Jawa Tengah ini memiliki potensi yang besar dalam mengembangkan IKM yang ada di Kabupaten Brebes hal ini di tunjukan dengan banyaknya karya karya masyarakat Kabupaten Brebes yang diminati oleh kolektor dari luar daerah seperti Jakarta, Bandung, Medan dll.

Masalah utama yang dihadapi oleh IKM di Kabupaten Brebes adalah pemasaran. Pemasaran dengan menggunakan metode konvensional memerlukan biaya yang tinggi, misalnya membuka cabang baru, ikut pameran, penyebaran brosur dll serta masih banyaknya produsen yang belum menguasai cara mempromsikan serta memasarkan produknya melalui internet. sehingga dapat dikatakan bahwa para pelaku IKM di Kabupaten Brebes belum memaksimalkan pemanfaatan teknologi informasi dalam pemasaran secara online yang sering disebut ecommerce. Untuk menunjang perekonomian di Kabupaten Brebes khususnya untuk pelaku IKM, agar memperoleh pasar yang lebih luas perlu dibangunya e-commerce untuk meyatukan para pelaku IKM, dengan memanfaatkan pasar online di Kabupaten Brebes secara langsung memberikan dampak positif untuk meningkatkan perekonomian di Kabupaten Brebes serta mendukung program pemerintah dalam 
Menghadapi pangsa pasar yang semakin maju yaitu Masyarakat Ekonomi Asia (MEA).

\section{Metode Penelitian}

Dalam penelitian ini menggunakan metode SDLC (System Development Life Cycle) dengan tahapan sebagai berikut (Blanchard\& Fabrycky, 2006):

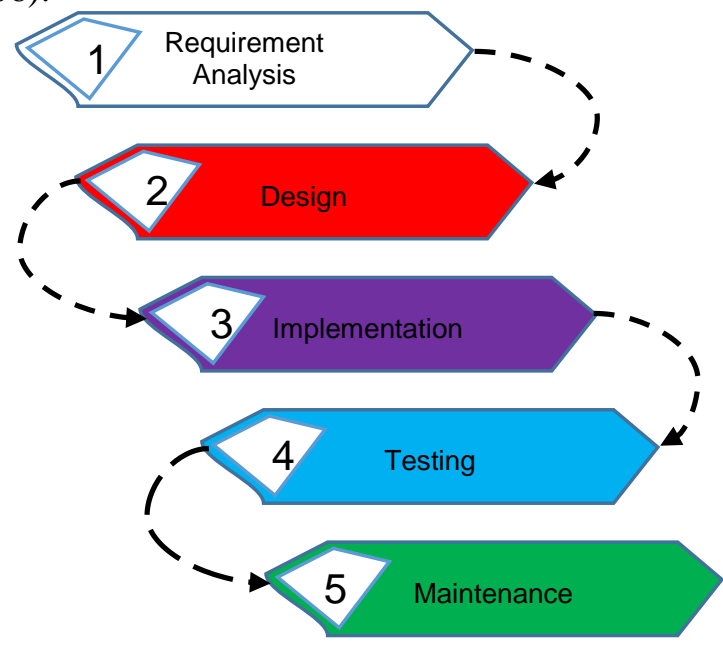

Gbr. 1 Model Waterfall SDLC (System Development Life Cycle)

A. Requirements Analysis

Tahap ini adalah tahap penentuan halhal penting sebagai dasar dari permasalahan yang akan dianalisis. Dalam tahap ini dilakukan identifikasi masalah, pengumpulan data berupa studi literatur, wawancara dan observasi, menentukan kebutuhan sistem, mengevaluasi berbagai solusi alternatif dan melakukan verifikasi data serta menentukan model data yang akan digunakan dan model proses yang akan diterapkan.

B. Design

Tahap ini merupakan tahap pengembangan setelah analisis sistem dilakukan. Sistem yang akan dibuat adalah prototype peringatan bahaya banjir disekitar kali pemali Brebes yang dirancang menggunakan alat bantu Flowchat untuk menggambarkan alur program.

C. Implementation

Hasil dari pembuatan prototype ini akan diuji cobakan kan terlebihdahulu dalam bentuk simulasi untuk menilai kekurangan yang ada. Dan hasil dari uji coba tersebut akan diimplementasikan atau di terapkan di tempat atau lokasi yang sebenarnya yaitu di sekitar kali pemali.
D. Testing

Setelah tahapan implementasi selesai dikerjakan, tahap selanjutnya adalah dengan melakukan pengujian hasil implementasi, yaitu dengan melakukan pengamatan visual pada alat melalui interface yang di gunakan,.

E. Maintenance

Tahapan terakhir dalam sistem ini adalah melakukan pemeliharaan diantaranya yaitu dengan memperbaiki sistem yang error, memperbaiki sensor atar peralatan elektronik lainya serta menjaga sistem dari kemungkinan masalah di masa yang akan datang

\section{Hasil dan Pembahasan}

Pembuatan e-commerce IKM Kabupaten Brebeas dibagi menjadi tiga tahapan yaitu analisis kebutuhan data, tahap perancangan dan tahap implementasi [5]

A. Analisis dan perancangan

Objek yang dijadikan pada penelitian ini adalah Dinas Perindustrian dan Tenaga Kerja Kabupaten Brebes serta Dinas Koperasi, Usaha Mikro dan Perdagangan Kab. Brebes. Analisis dilakukan dengan melakukan observasi dan wawancara untuk medapatkan dapat yang diperlukan dalam penelitian yang kemudian dirancang menggunakan UML (Unified Modeling Language), diagram yang digunakan adalah diagram usecase dan class diagram. Gambar dibawah ini menunjukan usecase diagram untuk Rancang Bangun E-commerce sebagai Sarana Peningkatan Perekonomian bagi Industri Kecil dan Menengah di Kabupaten Brebes. Dalam diagram tersebut terdapat empat aktor diantaranya, pengunjung, pelanggan, pelaku IKM dan super admin yang dapat mengakses website dengan kebijakan dan hak masing masing fungsionalitas berbeda..

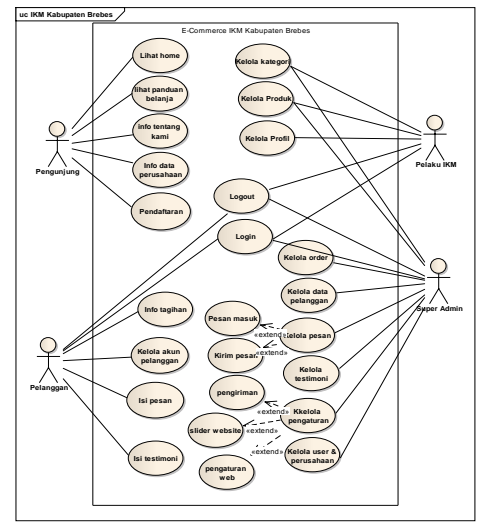

Gbr. 2 Usecase Diagram 
Untuk mengabarkan hubungan antara objek dengan objok yang lainya dalam sistem ini di gambarkan dengan class diagram seperti gambar dibawah ini. Terdapat tujuh kelas yang masing masing terdata atribut dan method yang saling berhubungan sehingga membuat satu kesatuan sistem yang saling berelasi.

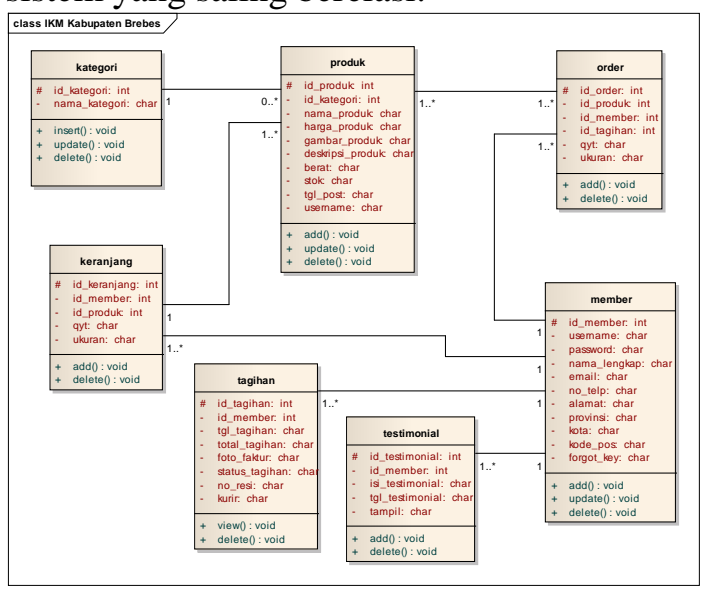

Gbr. 3 Class diagram

B. Implementasi

1. Interface form login

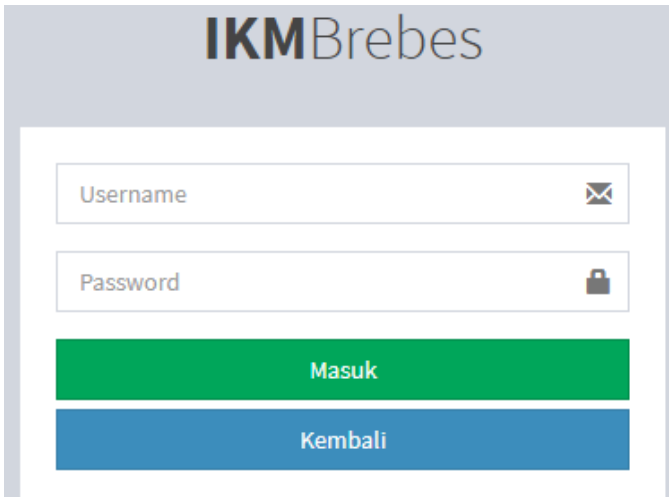

Gbr. 4 Form login pelaku IKM dan super admin

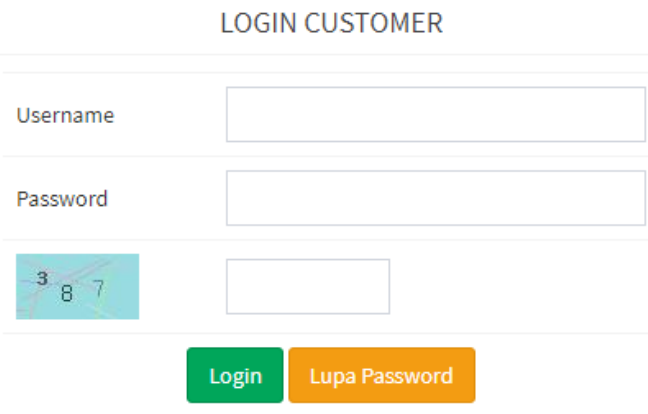

Belum Punya Akun? Silahkan Daftar Disini

Gbr. 5 Form login member
2. Interface pengunjung atau pelanggan

Ini merupakan tampilan pengunjung dan pelanggan ketika akan melihat produk IKM serta tampilan saat order INDUSTRI KECIL MENENGAH KABUPATEN BREBES

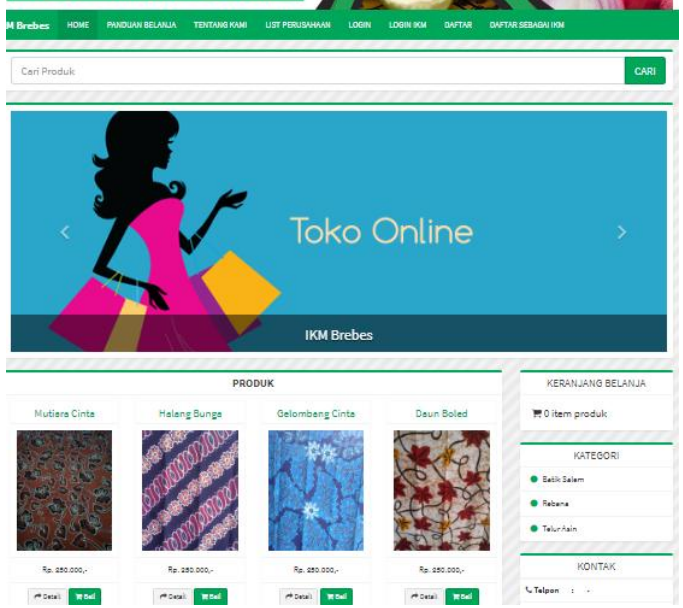

Gbr. 6 Halaman pengunjung dan member

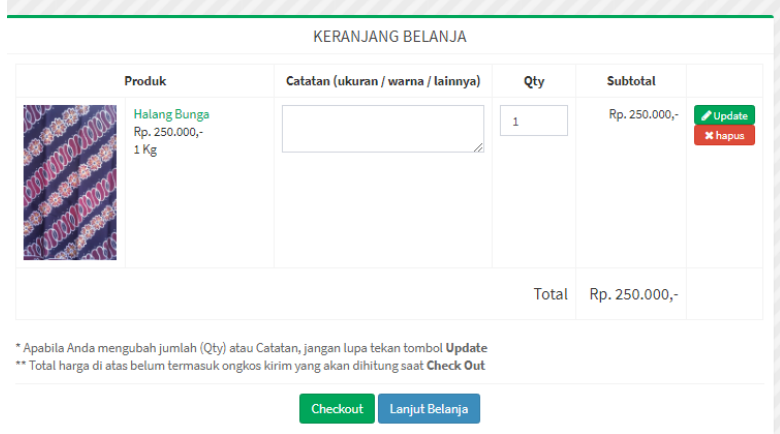

Gbr. 7 Halaman order atau beli

3. Interface form tambah kategori

Form ini digunakan untuk menambah kategori barang yang akan di jual yang dapat mengakses halam ini adalah IKM dan super admin.

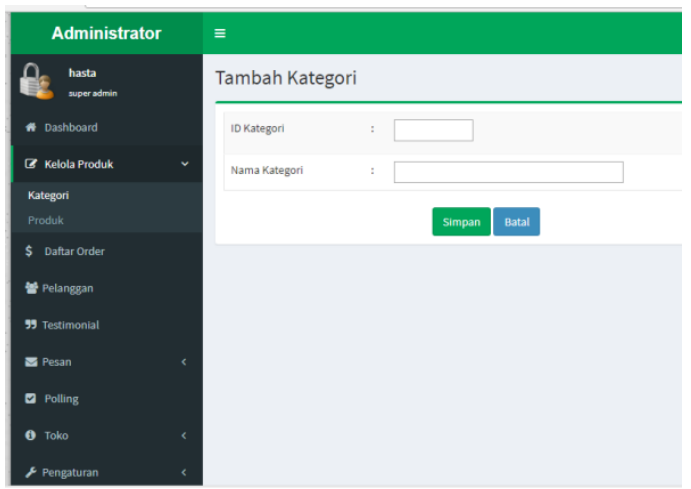

Gbr. 8 Halaman pelaku IKM 
4. Interface super admin

Form ini digunakan untuk menambah data barang yang akan di jual, yang dapat mengakses halam ini adalah IKM dan super admin.

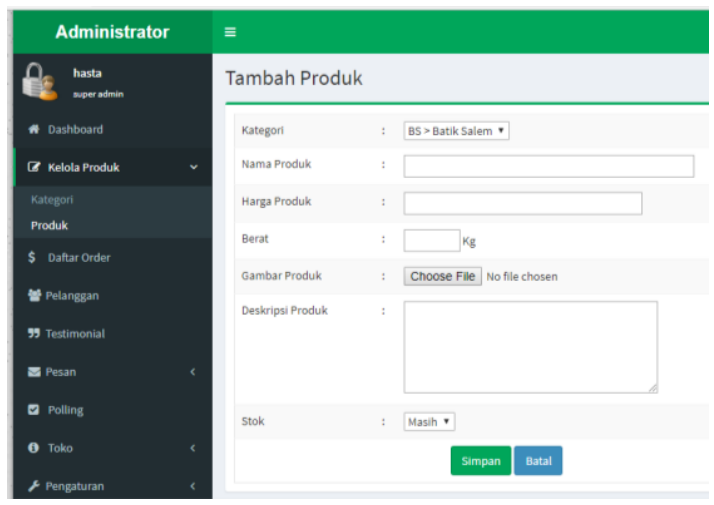

Gbr. 10 Halaman super admin

C. Pengujian

Pengujian dilakukan dengan menggunakan metode black box, Berikut ini adalah table pengujianya

Tabel 1

Pengujian black box

\begin{tabular}{|c|c|c|c|}
\hline No & Fungsi & Keterangan & Status \\
\hline 1 & $\begin{array}{l}\text { Form } \\
\text { Login }\end{array}$ & $\begin{array}{l}\text { Deskripsi } \\
\text { Form yang digunakan } \\
\text { untuk masuk ke } \\
\text { halaman member, } \\
\text { dengan memasukan } \\
\text { username dan } \\
\text { password } \\
\text { Prosedur pengujian } \\
\text { login user measukan } \\
\text { username dan } \\
\text { password, jika data } \\
\text { benar maka akan } \\
\text { masuk ke halaman } \\
\text { member }\end{array}$ & Sukses \\
\hline 2 & Logout & $\begin{array}{l}\text { Deskripsi } \\
\text { Digunakan untuk } \\
\text { keluar dari halaman } \\
\text { website } \\
\text { Prosedur pengujian } \\
\text { Dengan memilih } \\
\text { menu keluar maka } \\
\text { akan masuk ke } \\
\text { halaman form login }\end{array}$ & Sukses \\
\hline 3 & $\begin{array}{l}\text { Form } \\
\text { Pendaft } \\
\text { aran }\end{array}$ & $\begin{array}{l}\text { Deskripsi } \\
\text { Form pendaftaran } \\
\text { digunakan } \\
\text { pengunjung untuk } \\
\text { menjadi member agar } \\
\text { dapat membeli } \\
\text { barang } \\
\text { Prosedur Pengujian } \\
\text { Pengunjung mengisi } \\
\text { data yang tersedia }\end{array}$ & Sukses \\
\hline
\end{tabular}

\begin{tabular}{|c|c|c|c|}
\hline No & Fungsi & Keterangan & Status \\
\hline & & \begin{tabular}{lr}
\multicolumn{2}{l}{ dengan lengkap, jika } \\
berhasil aka di \\
simpan & ditabel \\
member & dan \\
pengunjung & bias \\
login. &
\end{tabular} & \\
\hline 4 & $\begin{array}{l}\text { Form } \\
\text { Tambah } \\
\text { Kategor } \\
\text { i }\end{array}$ & $\begin{array}{lr}\text { Deskripsi } \\
\text { Form } & \text { tambah } \\
\text { kategori digunakan } \\
\text { pelaku IKM dan } \\
\text { super admin untuk } \\
\text { menambah kategori } \\
\text { jenis barang yang } \\
\text { akan dijual } \\
\text { Prosedur Pengujian } \\
\text { Pelaku IKM dan } \\
\text { super admin memilih } \\
\text { menu kn tambah } \\
\text { kategori kemudia } \\
\text { mengisi ID kategori } \\
\text { dan nama kategori } \\
\text { jika berhasil akan di } \\
\text { simpan di table } \\
\text { kategori kemudian } \\
\text { kategori r yang } \\
\text { ditambahkan akan } \\
\text { muncul di halaman } \\
\text { kategori }\end{array}$ & Sukses \\
\hline 5 & $\begin{array}{l}\text { Form } \\
\text { Tambah } \\
\text { Produk }\end{array}$ & $\begin{array}{l}\text { Deskripsi } \\
\text { Form tambah } \\
\text { kategori digunakan } \\
\text { pelaku IKM dan } \\
\text { super admin untuk } \\
\text { menambah produk } \\
\text { yang akan dijual } \\
\text { Prosedur Pengujian } \\
\text { Pelaku IKM dan } \\
\text { super admin memilih } \\
\text { menu tambah produk } \\
\text { kemudian mengisi } \\
\text { data sesuai dengan } \\
\text { variable yang ada jika } \\
\text { berhasil data akan } \\
\text { disimpan di table } \\
\text { produk kemudian } \\
\text { akan tampil di } \\
\text { halaman pengunjung } \\
\text { ataumember }\end{array}$ & Sukses \\
\hline 6 & Beli & $\begin{array}{l}\text { Deskripsi } \\
\text { Menu beli digunakan } \\
\text { oleh member ketika } \\
\text { akan membeli barang } \\
\text { yang diinginkan } \\
\text { Prosedur Pengujian } \\
\text { Member memilih } \\
\text { barang yang akan } \\
\text { dibeli lalu pilih menu } \\
\text { beli kemudian } \\
\text { masukan keterangan }\end{array}$ & Sukses \\
\hline
\end{tabular}




\begin{tabular}{|c|c|c|c|}
\hline No & Fungsi & Keterangan & Status \\
\hline & & $\begin{array}{l}\text { yang di inginkan } \\
\text { seperti warna, ukuran } \\
\text { dll serta jumlah } \\
\text { barang yang akan } \\
\text { dibeli jika berhasil } \\
\text { maka akandisimpan } \\
\text { di keranjang belanja } \\
\text { serta melakukan } \\
\text { konfirmasi } \\
\text { pembayaran }\end{array}$ & \\
\hline 7 & $\begin{array}{l}\text { Form } \\
\text { Pesan }\end{array}$ & $\begin{array}{lr}\text { Deskripsi } & \\
\text { Form } & \text { Pesan } \\
\text { digunakan } & \text { member } \\
\text { untuk } & \text { memesan } \\
\text { barang } & \\
\text { Prosedur } & \\
\text { Member } & \text { memiian } \\
\text { menu } & \text { pesan } \\
\text { kemudian mengisi } \\
\text { judul da nisi pesan } \\
\text { jika berhasil data } \\
\text { akan disimpan di } \\
\text { tabel pesan dan } \\
\text { ditampilkan } \\
\text { halaman super didmin }\end{array}$ & Sukses \\
\hline 8 & $\begin{array}{l}\text { Form } \\
\text { Testimo } \\
\text { ni }\end{array}$ & $\begin{array}{lr}\text { Deskripsi } \\
\text { Form } & \text { Testimoni } \\
\text { digunakan } & \text { member } \\
\text { untuk } & \text { mengisi } \\
\text { testimoni } & \\
\text { Prosedur } & \\
\text { Mengujer memian } \\
\text { menu mestimony } \\
\text { kemudian muncul } \\
\text { form testimony lalu } \\
\text { di isi jika benar data } \\
\text { akan disimpan di } \\
\text { tabel testimony dan } \\
\text { tampil di halaman } \\
\text { super admin }\end{array}$ & Sukses \\
\hline
\end{tabular}

\section{Kesimpulan}

Penelitian ini bertujuan membangun sebuah website e-commerce untuk pelaku Industri Kecil dan Menengah (IKM) di Kabupaten Brebes. Metodologi yang diterapkan dalam membangun website website ini adalah metode SDLC (System Development Life Cycle) dengan mengunakan pengujian metode black box untuk fungsionalitas dari tiap tiap fitur. Hasil pengujian menunjukan bahwa tiap tiap fitur pada sistem telah berfungsi dengan baik sehingga IKM Kabupaten Brebes dapat melakukan proses transaksi dan promosi secara online sehingga dapat meningkatkan pendapatan para pelaku IKM di Kabupaten Brebes.Data ketinggian air yang telah diolah oleh raspberry kemudian akan di tampilkan melalui interface raspberry yang di koneksikan melalui wifi yang dapat di akses melalui smart phone.

\section{Daftar Pustaka}

[1] Gita Indah Marthasari Diah Risqiwati, Tri Buana Tungga Dewi RANCANG BANGUN DAN IMPLEMENTASI WEBSITE WEBSITE UKM GS4 MALANG MENGGUNAKAN METODE PROTOTYPING [Conference]// Seminar Nasional Teknologi dan Rekayasa (SENTRA). - Malang: Program Studi Teknik Informatika Universitas Muhammadiyah Malang, 2017.

[2] Nuryanti, J.M.F.E.U., Peran Website untuk Meningkatkan Daya saing Usaha Kecil Menengah (UKM) 2013.

[3] Jauhari Jaidan UPAYA PENGEMBANGAN USAHA KECIL DAN MENENGAH (UKM) DENGAN MEMANFAATKAN WEBSITE [Journal]. - Palembang: Jurnal Sistem Informasi (JSI), 2010. - Vol. 2.

[4] Blanchard, B. S., \& Fabrycky, W. J.(2006) Systems engineering and analysis (4th ed.) New Jersey: Prentice Hall.

[5] Hartman, Amir, John G. Sifonis, and John Kador. Net Ready: Strategies for Success in the E-conomy. New York: McGraw-Hill, 2000.

[6] Website Untuk Pemasaran Produk Usaha Kecil dan Menengah. Nugrahani, Dewi Shanti. Purworejo: SEGMEN Jurnal Manajemen dan Bisnis, 2011. 1.

[7] Teknologi Website dalam Proses Bisnis. Wirdasari, Dian. s.l. : SAINTIKOM, 2009, Vol. 7. 2.

[8] Desain Marketing Information Systems Pada Usaha Mikro Kecil Dan Menengah (UMKM) Di Desa Taman Sari Kabupaten Banyuwangi. A.A Gde Satia Utama, Izzato Millati. Prosiding Seminar Nasional, ISBN 978-602-60569-2-4.

[9] Sistem Website Bagi Usaha Mikro Kecil dan Menengah. Winarno, Jurnal Studi Manajemen Dan Bisnis, Vol 2 No. 1 Tahun 2015.

[10] Perancangan Sistem Website Untuk Produk Pembuatan Kue. Sandi Kosasi, CSRID Journal, Vol.7 No.1 Februari 2015, Hal. 5565 